\title{
Methodological Considerations for Furthering the Understanding of Constraints in Applied Sports
}

\author{
Peter Browne ${ }^{1,2^{*}}$, Alice J. Sweeting ${ }^{1,2}$, Carl T. Woods ${ }^{1}$ and Sam Robertson ${ }^{1,2}$
}

\begin{abstract}
Commonly classified as individual, task or environmental, constraints are boundaries which shape the emergence of functional movement solutions. In applied sport, an ongoing challenge is to improve the measurement, analysis and understanding of constraints to key stakeholders. Methodological considerations for furthering these pursuits should be centred around an interdisciplinary approach. This integration of methodology and knowledge from different disciplines also encourages the sharing of encompassing principles, concepts, methods and data to generate new solutions to existing problems. This narrative review discusses how a number of rapidly developing fields are positioned to help guide, support and progress an understanding of sport through constraints. It specifically focuses on examples from the fields of technology, analytics and perceptual science. It discusses how technology is generating large quantities of data which can improve our understanding of how constraints shape the movement solutions of performers in training and competition environments. Analytics can facilitate new insights from numerous and complex data through enhanced non-linear and multivariate analysis techniques. The role of the perceptual sciences is discussed with respect to generating outputs from analytics that are more interpretable for the end-user. Together, these three fields of technology, analytics and perceptual science may enable a more comprehensive understanding of constraints in sports performance.
\end{abstract}

Keywords: Interdisciplinarity, Sports technology, Analytics, Perceptual science, Ecological dynamics

\section{Key Points}

- The fields of technology, analytics and the perceptual sciences offer opportunities to further the understanding of constraints in applied sport.

- Developments in the fields of technology, analytics and the perceptual sciences can accelerate the benefits of an interdisciplinary approach to some of sport's most pervasive performance questions and challenges.

\footnotetext{
* Correspondence: peter.browne2@live.vu.edu.au

'Institute for Health and Sport (iHeS), Victoria University, Footscray,

Melbourne, Victoria, Australia

${ }^{2}$ Western Bulldogs Football Club, Footscray, Melbourne, Australia
}

\section{Introduction}

Sport science, in general, has long been criticised for its insular nature, with various sub-disciplines typically looking to solve existing problems internally [1-5]. In research, this has manifested in the establishment and reproduction of sub-discipline-specific methodologies $[6$, 7]. In practice, this is often observed in the separation of departments (e.g. strength and conditioning, medical and performance analysis) in high-level sporting organisations, culminating in isolated and siloed thinking [8, 9]. These issues may be due to a variety of reasons, such as disciplines researching sport at varying levels from molecular to the environment, whilst also applying discipline-specific terminology $[1,7]$. Within the tertiary education sector, the fast growth of sport science has led
Springer Open (c) The Author(s). 2021 Open Access This article is licensed under a Creative Commons Attribution 4.0 International License, which permits use, sharing, adaptation, distribution and reproduction in any medium or format, as long as you give appropriate credit to the original author(s) and the source, provide a link to the Creative Commons licence, and indicate if changes were made. The images or other third party material in this article are included in the article's Creative Commons licence, unless indicated otherwise in a credit line to the material. If material is not included in the article's Creative Commons licence and your intended use is not permitted by statutory regulation or exceeds the permitted use, you will need to obtain permission directly from the copyright holder. To view a copy of this licence, visit http://creativecommons.org/licenses/by/4.0/. 
to a focus on specialisation $[10,11]$, which has partially been attributed to the lack of an overarching, unifying framework [7, 11]. Furthermore, current practices are often seen to offer the illusion of integration, but do not fully combine methods and techniques alongside theories and concepts [1].

Accordingly, there have been numerous calls for sport science to progress beyond this insularity and embrace an inter- and even transdisciplinary approach $[2,5,7$, 12-15]. Adoption of an interdisciplinary approach in sport, whilst challenging, could serve to (i) coordinate and unify activity, (ii) communicate translatable ideas coherently and (iii) design and quantify activities which support the emergence of complex and adaptive behaviours $[1,7,8,14]$. For instance, if practitioners could operate more collaboratively, it could improve the allocation of time and resources by limiting the duplication of data collection and analysis. Data and its subsequent analysis could also be better communicated through consistent language which may aid the transfer of concepts and ideas between disciplines [8]. Through this, an enhanced ability to address some of sport's most pervasive performance questions and challenges could be gained.

A true interdisciplinary approach would see sports performance disciplines working collaboratively to fully encompass principles, concepts, data and methods to solve problems and support practice [7]. This could result in enhancements of learning, which could then be shared between a range of operational areas, like talent identification, talent selection, performance analysis and coaching $[14,16]$. Independent methodologies and measurement techniques could be reconciled to build upon and learn from one another. Interdisciplinarity offers collaborative problem-solving which may potentially lead to enhanced inquisition, the identification of new questions and the resolving of existing problems [10]. For interdisciplinarity to occur, new methods and procedures are required, which may challenge engrained and culturally pervasive disciplinary norms.

Frameworks such as ecological dynamics or Newell's constraint model offer a basis upon which sports performance can be measured [7, 17]. Either has the ability to act as a vehicle upon which an interdisciplinary approach could be implemented [18], and may aid the alignment of methods and data [7]. Ecological dynamics is the integration of concepts from ecological psychology [19], complexity sciences [20] and coordination dynamics [17, 21]. Newell's constraint model [17] and its application views skill, learning, development and expertise as emergent properties of a functionally adaptable and evolving relationship formed between an individual and the constraints of their environment [22]. It is noteworthy that these rationales are not localised to a single sport science discipline; rather, they seek to enhance the understanding of related concepts such as skill, performance, learning and expertise [23].

Constraints are understood as the boundaries which shape the emergence of functional movement solutions [24] and are commonly classified into individual, task and environmental categories [17]. Individual constraints can be defined as structural (e.g. body dimensions, technical attributes), historical (e.g. development of resilience, experience) and/or functional (e.g. motivation, cognition) [24-26]. Task constraints are typically defined as rules (e.g. laws of the game, boundary markings), task goals and/or instructional features (e.g. coach instruction or umpire feedback) [25, 27-29]. Environmental constraints can be physical (e.g. weather, light, gravity) or sociocultural (e.g. values, cultural beliefs, peer support) $[24,26,30]$. It has been proposed that task constraints are emergent properties of a system which are able to be distributed between the individual and environment [31]. Moreover, constraints have been hypothesised to interact and be correlated via circular causality and can be nested based on characteristic time-scales [31].

An understanding of the manipulation of constraints and their impact on skilled performance is, therefore, central to the design of activities intended to promote performance and learning in sport. This can be achieved through the manipulation of constraints to design representative practice tasks which preserve key informationmovement couplings experienced during competition. However, a central feature of constraints and their impact on emergent movement solutions relates to their interaction $[23,24]$. The interaction between constraints is often misunderstood in both practice and research given previous methodological limitations relating to their measurement and interpretation [7]. A methodological limitation is the collection of discrete events without accounting for constraints or the context influencing these events [32]. For example, how do constraints such as time in possession, pressure type, playing at home or away and/or fatigue state interact to influence the emergence of skilled actions in team sports [32]? Future research could overcome this through the use of technology to capture constraints like these and then applying a multivariate analysis technique, could help practitioners understand their influence on emergent behaviour.

Fortunately, for multiple reasons, an interdisciplinary approach to measuring constraints in applied sport is arguably more feasible now than ever before. Recent improvements in a number of seemingly disparate fields and disciplines have the potential to progress this opportunity. Using examples from technology, analytics and the perceptual sciences, this review details how advancements in a range of fields can be leveraged to achieve 
interdisciplinarity and disciplinary integration in highperformance sport.

\section{Technology}

Ongoing, and recently accelerated, improvements in the field of technology have enhanced the measurement of almost all aspects of sport [33]. Sport science disciplines, including coaching and performance analysis, have traditionally used largely manual methods to measure constraints in practice and competition. However, technology has made it possible to capture these constraints more efficiently and accurately as well as in a more detailed manner [7]. These improvements have impacted a range of disciplines, leading to the manufacturing of better-quality hardware, increased feasibility of athlete tracking and enabling the automated capture of events through computer vision. For instance, developments such as video annotation software enabled practitioners to move from pencil, paper and stopwatch techniques to facilitating the recording of match events and corresponding contextual information in greater detail [34]. More recent technological developments have enabled the capture of an athlete's location on a playing field through global and local positioning systems as well as optical technologies [35, 36]. Presently, such systems are now capable of providing semi- or automated detection of athlete actions $[37,38]$.

In addition to incremental improvements, some technological developments have facilitated the identification and measurement of variables and metrics which were previously unrecognised in research and practice. For example, eye-tracking, the detection of emotion in competition $[39,40]$ and automatic marker-tracking systems [36, 37] have offered insight into the non-linear and complex interaction between variables in near realtime-clarity which is not possible with the human eye alone [41, 42]. Consequently, the number of individual constraints which can be recorded has continued to grow with the development and implementation of technology. A selection of these constraints is reported in Table 1. As technology continues to develop, so too will the opportunities to improve the quality of constraint measurements. Further opportunities exist to develop these technologies with knowledge from other disciplines such as agriculture, city planning and the military (Table 1). However, as observations are embedded in context, the measurement and collection of reliable constraint data is required to take place without losing the validity required for scientific rigour and thereby aid in promoting experimental representative design [107].

To represent the influence of technology on the measurement of constraints, the concept of pressure in a team sport context presents a useful example. As a scientific construct, pressure has been measured in multiple ways; through the proximity of opponents on the field as measured by player tracking systems [104, 108], an athlete's physiological and emotional response measured via sensors $[39,56]$ or the context of a game via the scoreboard or time remaining $[48,90]$. Adding more data types to define pressure more comprehensively will likely lead to a greater understanding of its influence on performance outcomes.

Extending these ideas, technology can enable greater clarity with regards to the measurement of constraints players experience during competition. Beyond helping practitioners contextualise actions observed during competition, it can assist with the design of practice tasks that are more representative of the requirements of competition to support athlete development and learning [109]. For example, by understanding the key constraints that shape athlete behaviour, practitioners could design them into practice tasks, thereby preserving information-movement couplings to support athletes in becoming more self-regulating in performance [110].

Of course, both researchers and practitioners will always experience some limitations with respect to the volume of data they collect. Furthermore, the continual addition of new types of data has the potential to overcomplicate modelling and limit user interpretability [111]. From a resourcing perspective, it may not be feasible to collect all possible data sources in training or competition environments. In some cases, the feasibility of measurement may be influenced by the sport itself. For example, whilst an inertial movement unit could provide insight into constraints and contextual factors surrounding limb motion, most governing sports organisations restrict the use of such devices during competition [112]. Additionally, ball tracking systems in team sports are becoming more commonplace in practice, yet the resources to analyse and interpret the outputs remain intensive $[109,113]$. Thus, finding a feasible 'sweet spot' for the collection of data is required in practice to enable the most impactful implementation of technology.

\section{Analytics}

One criticism leveraged at ecological dynamics points towards its complexity, with research to date being largely conceptual or performed in a laboratory [114]. The measurement of constraints in practice has often been reductionist in approach [107], emphasising either one or two constraints that are measured in isolation [32]. This can provide rigour in relation to the methodological approach; however, it is less representative of the environment being explored [107]. This may result in an overly narrow and potentially even misleading interpretation of sports performance by not accounting for, or misrepresenting, the nuances of a complex system [115- 


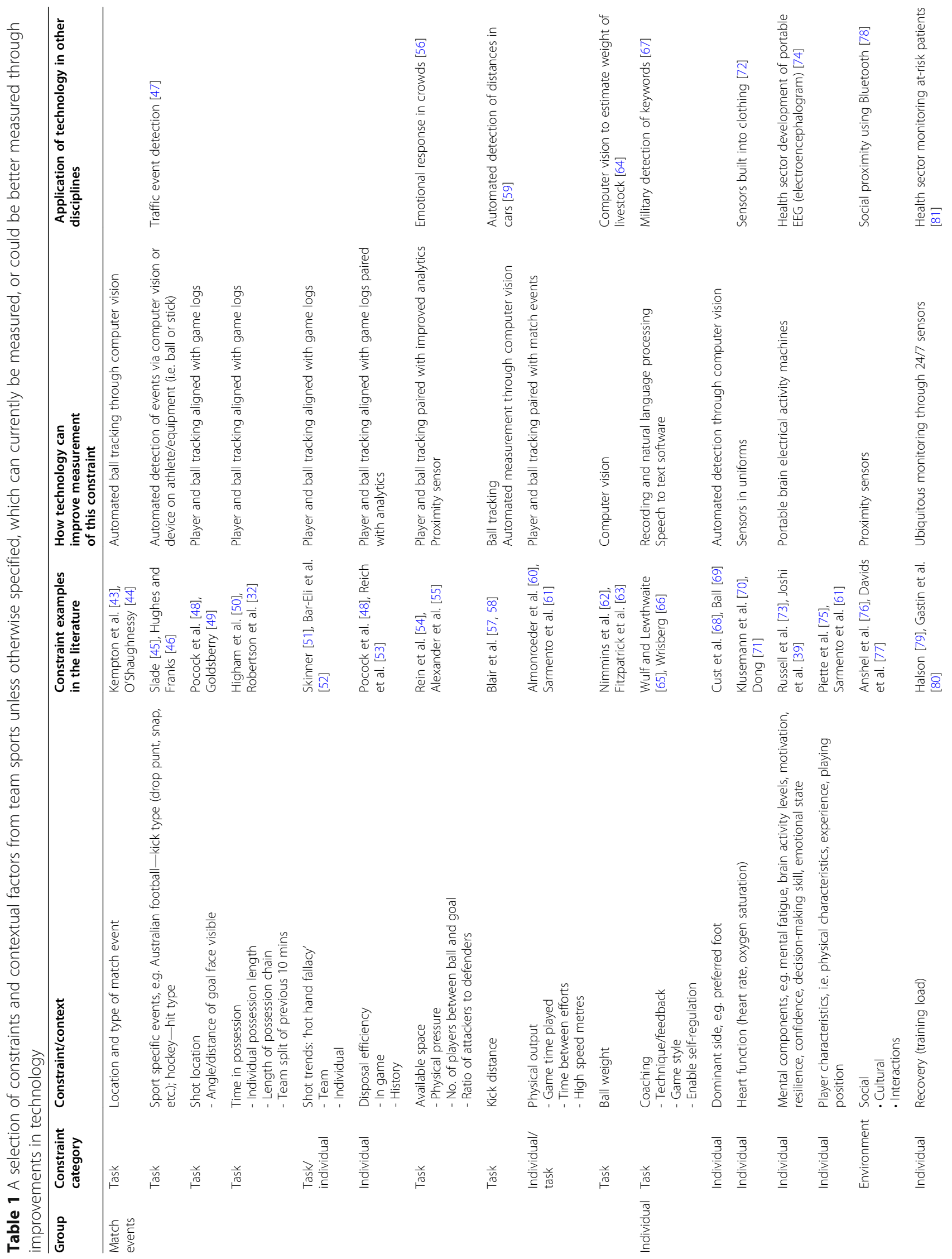




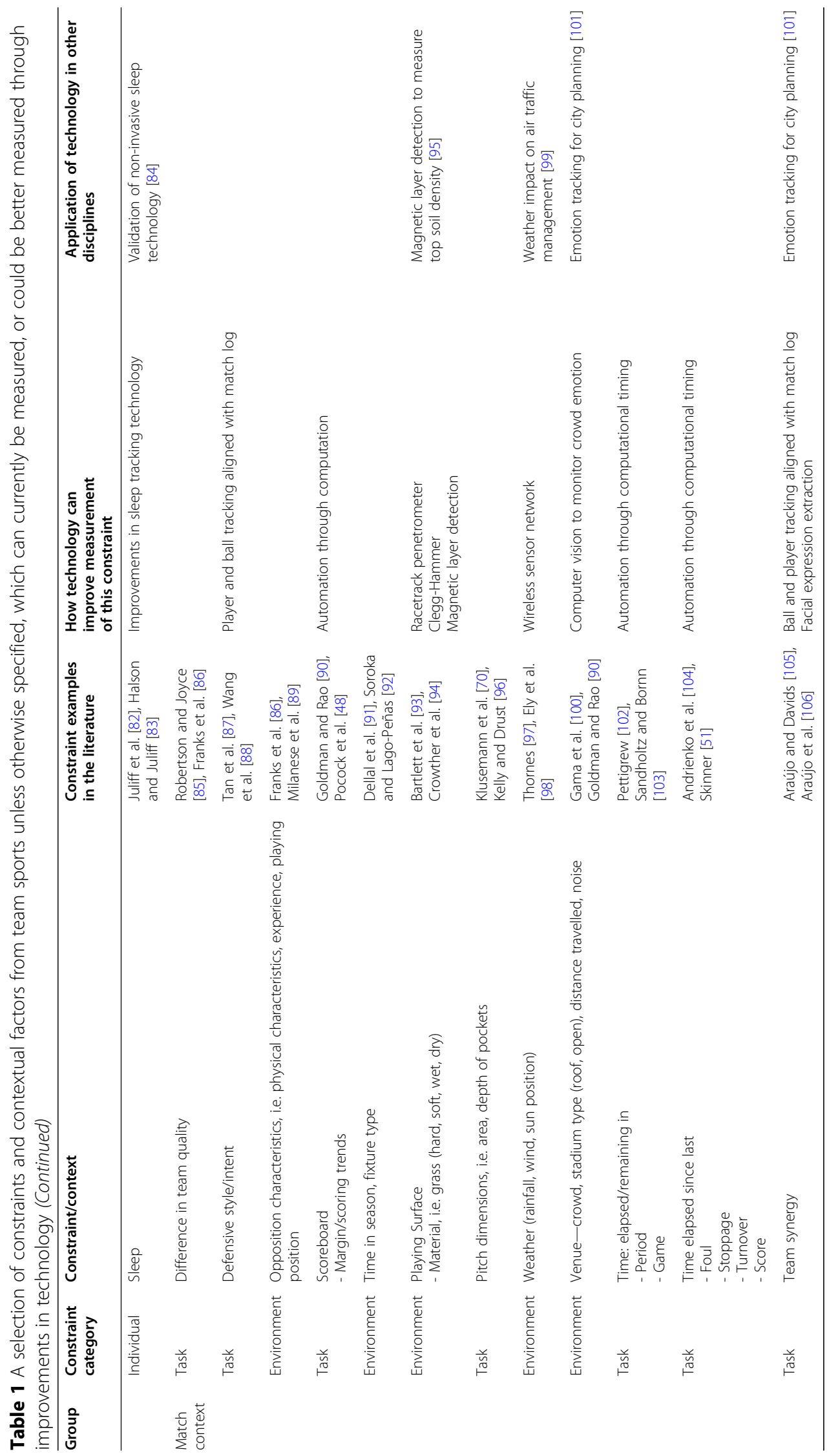


117]. Thus, whilst the literature referred to in Table 1 is encouraging with respect to the large volume of constraints captured in performance settings, it is important to recognise that (i) constraints do not act or interact independently and (ii) not everything can be measured and analysed in research or practice.

Analytics refers to the methods based on the computation of statistics and data [118] and, therefore, considers both computation and algorithms. Machine learning, the application of artificial intelligence that affords a system the ability to autonomously learn through experience or example data, has had increased application in sport [119]. Analytics may aid sport science practices in identifying complex and non-linear patterns within datasets. Machine learning techniques have been used in sport to quantify defensive patterns [37], as well as predict events $[48,120]$ and match outcomes $[120,121]$. Improved analytical methodologies allow for more complex phenomena, such as the interaction of players, to be measured $[36,122]$. Accordingly, analytical approaches applied are an important aspect of performance research and decision-making [123-125], supporting the experiential knowledge of professional practitioners. To make analytics applicable to industry settings, practitioners may need enhanced skillsets to use data tools which can analyse and summarise big datasets and/or seek to establish bespoke workbooks that automate preferred data visualisations following data capture. In the time-constrained environment of high-performance sport, analytics may streamline decision-making across multiple departmental areas $[36,122,126]$.

A key benefit of analytics when applied to sports performance relates to its flexibility. Specifically, in regard to how different machine learning algorithms can often be used interchangeably on the same dataset [127-129]. This can enable a problem to be viewed through multiple lenses which may be implemented or visualised differently based on user preferences. Returning to the abovementioned example, it has been acknowledged that pressure has been analysed in various ways. For example, weighted densities paired with linear and quadratic functions have been used to understand defensive players' movements through spatiotemporal data in soccer [104], whereas in basketball, matrix factorisation and regression models have been utilised for the same purpose [86]. The creation and measurement of a pressure metric can be achieved with either discrete or continuous variables. Representation of pressure in a categorical format (i.e. 'high' or 'low') may make for easier stakeholder comprehension and implementation in the applied setting. Irrespective of the format in which the data are represented, however, more context than solely player movement is required to fully measure pressure. Thus, using player density or pitch control [130, 131], alongside score board margin, time remaining and individual traits of an athlete could offer greater insight into the pressure experienced at any given time.

The collection of more data related to different interacting constraints can ultimately make the analysis of variables more difficult. The principle of parsimony is critical within analytics to strike a balance between feasibility and obtaining a high-level understanding of phenomena of interest. Without enhanced analytical tools, the translation of model outputs which contain a large number of variables into meaningful information remains a challenge $[111,132]$. Parsimony relates to achieving a balance between collecting enough variables to sufficiently support an evaluation but not so many that only provide small improvements in understanding [133, 134]. Within sport, parsimony is vital to the uptake of new models and decision support systems, as it can reduce data redundancies and optimise time investments. For example, if a model requires five variables to achieve $80 \%$ accuracy on a given problem, the time and resources required to collect an additional ten variables to improve accuracy by $5 \%$, may not outweigh the benefit of a slightly less accurate model. This has useful applications in scenarios whereby a model requires implementation across multiple environments. For instance, comparing junior athlete performance with professional competition for team sport scouting purposes may see the user having access to differing levels of data, leading to a lack of direct comparability of performances. Many variables used within the professional competition may not be available at lower levels; thus, invoking the notion of parsimony forces the user to focus on including those variables that are not only the most important, but also readily available across all levels of competition.

Parsimony also helps to avoid problems with overfitting. Overfitting describes a model, which is generated specifically to a training dataset, but where the results are not generalisable or validated on a new or unseen test dataset [123, 135]. In the example above, a scouting model used in professional competition may show accurate predictive performance when applied to professional players, but due to its large number of inputs (amongst other factors) may generalise less well to other competition levels [124]. Striking a compromise between parsimony and model accuracy is a complicated exercise, particularly in the field, but is an increasingly important consideration as sports performance models become more complex and detailed.

\section{Perceptual Science}

The growth in data along with the enhanced analysis of these data have been emphasised to this point of the review. However, without the output from such analyses being appropriately communicated to and interpreted by 
key stakeholders, the gains achieved by sport science will go unrealised. Learnings from the perceptual sciences could hold the key to assist in this area. Perceptual sciences refers broadly to the integration of neuroscience, computer science and psychology with the aim to understand the link between external properties and cognition $[136,137]$. Specifically, components of cognitive science such as psychophysics, alongside the art of visualisations, may be used to enrich the interpretation of analytics and explain why some visualisations better enable the detection of key information. Together, the concepts of cognitive science and the perceptual sciences can provide a foundation and guide for the utilisation of the science and language of visualisations to maximise comprehension and improve the communication of complex phenomena in sport. In doing so, visualisations may enable the user to identify the relationship between an individual and their environment with enhanced clarity by preserving the complex and non-linear interactions at work, which are typically reduced through traditional, linear approaches.

Visualisations have been proposed as a method to leverage data communication to highlight findings clearly with precision and efficiency. This is required as despite the improvements in technology and analytics, a linear improvement in performance has not occurred [116]. This may be partially due to a user's reduced ability to gain insight from numerical data, as tables may be inferior to visualisations in communicating results [138]. Visualisations provide a tool to translate numbers into a simpler medium for ease of interpretation and implementation [136]. This may be due to the increased cognitive load required to comprehend numerical data compared with visualisations [136, 139]. Thus, as analytical model outputs become more complex, visualisations can help to support the user's comprehension. Ultimately, if such output is not interpretable or operationalisable, even the best performing model will not be implemented by key stakeholders in the applied setting $[113,134]$.

Given the inherent complexity of ecological dynamics, visualisations are critical in their ability to indirectly convey key information. Visualisations are an essential tool to enable the appreciation of complex and multidimensional constraints in a system. The ability to visualise multiple variables may further enhance the communication of complex information. For instance, five dimensions can be displayed and manipulated through the two regular axes as well as hue, shape and size of data points. The impact of visualisations on stakeholder decision-making has been examined in forecasting, communication and planning [140-143]. Furthermore, visualisation aesthetics have been linked with an individual's engagement, enjoyment and memorability [144-147]. However, an awareness of inherent biases is also required in the generation of visualisations. Biases are cognitions which prejudice decisionmaking [148]. For instance, as the number of components displayed in a bar chart increases, the accuracy with which the chart is interpreted decreases [149]. The transition from data and analysis to the creation of a visualisation may aid in the uptake of information and thus, insight in the applied setting [136].

Returning to the pressure example discussed in earlier sections, it is apparent that despite their visual potential, pressure or defensive actions are often reported as aggregate data, for example as a frequency count in a table [110, 150]. However, in scenarios whereby continuous pressure metrics have been proposed [104, 130], visualisations can be used in different ways to provide alternate insights with the same data. For example, Fig. 1 provides an example of how pitch control can be used to visualise pressure. Pitch control is a concept which defines the probability that an athlete or team has control of a specific point of a certain region of the pitch at a given time point [130]. It is based on athlete location, velocity and relative distance from the ball at a given time point, where the aggregate influence of each team's athletes is calculated on a continuous scale to provide a measure of pitch control [130]. Specifically, Fig. 1a shows an overview of a passer in football (represented by the white dot) at a discrete moment in time during a match. The darker the blue area the more pressure experienced by the passing player, based on their level of 'pitch control'. Such a visualisation can be used to provide further context to the pressure not just surrounding the passer, but the options available to them. Furthermore, the level of pitch control varies throughout a game, which can be visualised as a time series to display how pressure changes for the team in possession throughout a match (Fig. 1b). Thus, ' 1 ' would represent total pitch control by team 1, 0.5 represents equal levels of pitch control by both teams and ' 0 ' relates to total pitch control by team 2. Furthermore, visualising pitch control at the location of the passer and receiver may provide insight into game style, risk-taking behaviour and decision-making (Fig. 1c, d). For instance, a team may relinquish some pitch control at the location of the passer to create more space at the location of the receiver. This tactic may increase the pressure, or decrease pitch control, at the ball location but lessen the pressure for the receiver. Thus, visualisations may enable the facilitation of the improvements in technology and analytics to be realised. When operationalised in unison, they may help aid decision-making and encourage interdisciplinarity-demonstrated by this pressure example, which uses player tracking data alongside algorithms to generate a pitch control metric and visualisations to help convey these data in a usable format. Thus, appropriate visualisations using the same 
a

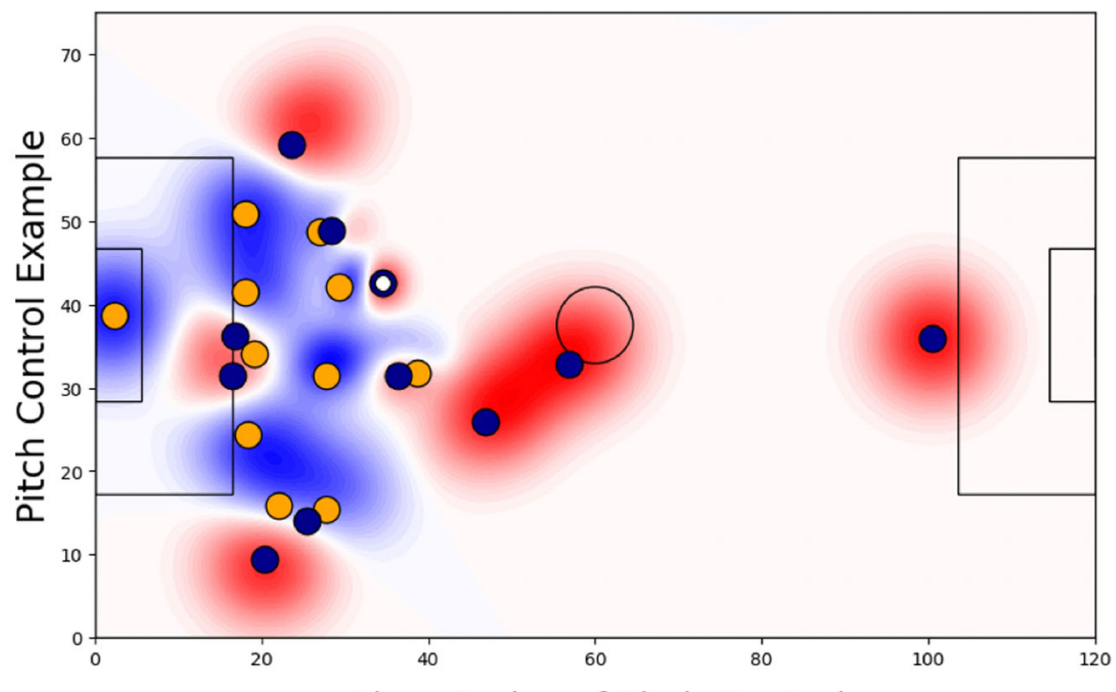

b

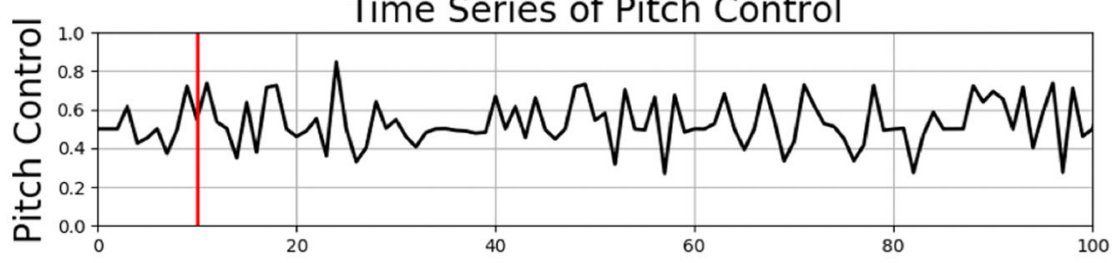

C

Pitch Control of Passers

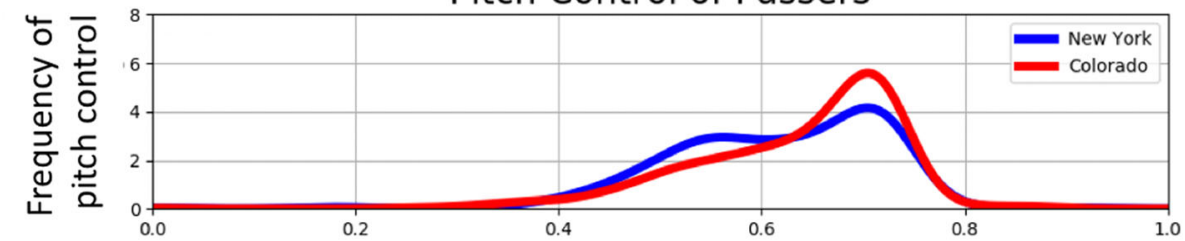

d

Pitch Control of Receivers

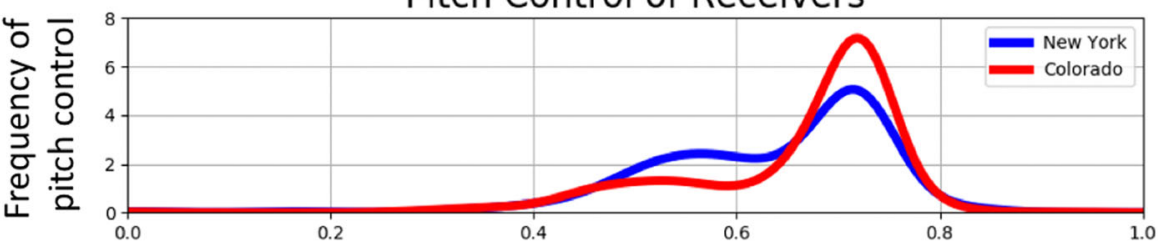

Fig. 1 Examples of different ways pressure may be visualised via an exemplar from football. The metric of pitch control is used, a concept which defines the probability that an athlete or team has control of a specific point. a Static image of the pitch with player locations and pitch control at the time indicated by the red line in $\mathbf{b}$. Ball possession is represented by the white circle. $\mathbf{b}$ Time series of pitch control of the attacking team calculated as a minute by minute average of pitch control over course of a game, where 1 represents total pitch control by team 1, 0.5 represents equal levels of pitch control of both teams and 0 relates to total pitch control by team 2 . The red line indicates the time a was taken from. c Density plot of the level of pitch control of passer. $\mathbf{d}$ Density plot of the level of pitch control of receiver

data or model can improve the communication of findings to key stakeholders and facilitate rapid interpretation and implementation $[139,151,152]$.

\section{Conclusion}

This narrative review has provided some methodological considerations for the measurement of constraints though an interdisciplinary approach. The benefits of an interdisciplinary approach could arise from greater consistency between disciplines, more efficient workflows and optimised communication procedures [8]. These improvements may allow for questions to be answered more completely, rather than solutions that have origins and applications in a single discipline. This narrative review specifically discussed how the continually developing fields of technology, analytics and perceptual sciences are situated to help guide and support sport science to make the integration between disciplines more feasible. Importantly, these fields are not all encompassing and many others exist which can further the measurement of constraints in applied sport. Whilst other 
fields may further the development of constraint measurement, interdisciplinarity can also be encouraged through applying an overarching framework [7]. By embracing a truly interdisciplinary approach, progress on many of sport science's most pervasive and important questions can be realised. However, for sport science to continue to progress towards interdisciplinarity, more needs to be done to create environments open to change, where improvements can transcend sub-disciplines. Furthermore, academic institutions need to provide training and education which are supportive of interdisciplinary approaches, as opposed to driving a continued discipline speciality. This may see highperformance sports organisations reassess structures, move away from siloing departments, towards creating integrated, functioning environments where time and resources are available to be utilised in an interactive way. The removal of such barriers may aid sport scientists in adopting the principles of interdisciplinarity.

\section{Abbreviations}

EEG: Electroencephalogram

\section{Acknowledgements}

The authors would like to thank Dr. Bart Spencer for his assistance and advice in the generation of Fig. 1.

\section{Code Availability}

Not applicable

\section{Authors' Contributions}

Conceptualization: PB and SR. Writing-original draft preparation: PB. Writing - review and editing: SR, AS, CW and PB. Supervision: AS and SR. The authors read and approved the final manuscript.

\section{Funding}

The authors declare that no funding was received for this review.

\section{Availability of Data and Materials}

Not applicable

\section{Declarations}

Ethics Approval and Consent to Participate

Not applicable-review article

\section{Consent for Publication}

Not applicable

\section{Competing Interests}

The authors, Peter Browne, Alice Sweeting, Carl Woods, and Sam Robertson, declare that they have no competing interests.

Received: 2 September 2020 Accepted: 7 March 2021

Published online: 01 April 2021

\section{References}

1. Balagué $N$, Torrents $C$, Hristovski R, Kelso J. Sport science integration: an evolutionary synthesis. Eur J Sport Sci. 2017;17(1):51-62. https://doi.org/10.1 080/17461391.2016.1198422.

2. Buekers M, Ibáñez-Gijón J, Morice AH, Rao G, Mascret N, Laurin J, et al. Interdisciplinary research: a promising approach to investigate elite performance in sports. Quest. 2017;69(1):65-79. https://doi.org/10.1080/0033 6297.2016 .1152982

3. Elliott B. Biomechanics: an integral part of sport science and sport medicine. J Sci Med Sport. 1999;2(4):299-310. https://doi.org/10.1016/S1440-244 0(99)80003-6.
4. Davids K, Handford C, Williams M. The natural physical alternative to cognitive theories of motor behaviour: an invitation for interdisciplinary research in sports science? J Sports Sci. 1994;12(6):495-528. https://doi.org/1 $0.1080 / 02640419408732202$

5. Burwitz L, Moore PM, Wilkinson DM. Future directions for performancerelated sports science research: an interdisciplinary approach. J Sports Sci. 1994;12(1):93-109. https://doi.org/10.1080/02640419408732159.

6. Cardinale M. Commentary on "Towards a Grand Unified Theory of sports performance". Human Mov Sci. 2017:56(Part A):160-2.

7. Glazier PS. Towards a grand unified theory of sports performance. Hum Mov Sci. 2017;56(Pt A):139-56. https://doi.org/10.1016/j.humov.2015.08.001.

8. Rothwell M, Davids K, Stone J, O'Sullivan M, Vaughan J, Newcombe D, et al. A department of methodology can coordinate transdisciplinary sport science support. J Expertise. 2020;3(1):55-65

9. Otte FW, Davids K, Millar S-K, Klatt S. Specialist role coaching and skill training periodisation: a football goalkeeping case study. Int J Sports Sci Coach. 2020;15(4):562-75. https://doi.org/10.1177/1747954120922548.

10. Hristovski R, Balagué N, Vázquez P. Experiential learning of the unifying principles of science through physical activities. In F. Miranda (Ed.), Systems theory: Perspectives, applications and developments. New York: Nova Science; 2014. p. 37-48

11. Hristovski R, Aceski A, Balague N, Seifert L, Tufekcievski A, Cecilia A. Structure and dynamics of European sports science textual contents: analysis of ECSS abstracts (1996-2014). Eur J Sport Sci. 2017;17(1):19-29. https://doi.org/10.1 080/17461391.2016.1207709.

12. Button C, Croft JL. Sports science needs more interdisciplinary, constraintsled research programmes: the case of water safety in New Zealand. Hum Mov Sci. 2017:56(Pt A):157-9. https://doi.org/10.1016/j.humov.2017.04.017.

13. Newell WH. A theory of interdisciplinary studies. Issue Interdiscip Stud. 2001; 19:1-25.

14. Piggott B, Müller S, Chivers P, Papaluca C, Hoyne G. Is sports science answering the call for interdisciplinary research? A systematic review. Eur J Sport Sci. 2019;19(3):267-86. https://doi.org/10.1080/17461391.2018.1508506.

15. Woods CT, Robertson S, Rudd J, Araújo D, Davids K. 'Knowing as we go': a hunter-gatherer behavioural model to guide innovation in sport science. Sports Medicine-Open. 2020;6(1):1-9.

16. Freedson P. Interdisciplinary research funding: reaching outside the boundaries of kinesiology. Quest. 2009;61(1):19-24. https://doi.org/10.1080/ 00336297.2009.10483597.

17. Newell KM. Constraints on the development of coordination. Motor Dev Child. 1986;34:341-60

18. Araújo D, Davids K, Hristovski R. The ecological dynamics of decision making in sport. Psychol Sport Exerc. 2006;7(6):653-76. https://doi.org/10.1 016/j.psychsport.2006.07.002

19. Gibson J. The theory of affordances. The ecological approach to visual perception. Boston: Houghton Miffin; 1979. p. 127-43.

20. Seifert L, Araújo D, Komar J, Davids K. Understanding constraints on sport performance from the complexity sciences paradigm: an ecological dynamics framework. Hum Mov Sci. 2017:56(Pt A):178-80. https://doi.org/1 0.1016/j.humov.2017.05.001.

21. Seifert L, Davids K. Ecological dynamics: a theoretical framework for understanding sport performance, physical education and physical activity. Tempe: CS-DC'15 World e-conference; 2015. ffhal-01291044f.

22. Williams AM, Hodges NJ. Skill acquisition in sport: research, theory and practice: Routledge; 2004. https://doi.org/10.4324/9780203646564.

23. Button C, Seifert L, Chow JY, Davids K, Araújo D. Dynamics of skill acquisition: an ecological dynamics approach. Champaign: Human Kinetics Publishers; 2020

24. Davids K, Button C, Bennett S. Dynamics of skill acquisition: a constraints-led approach. Champaign: Human Kinetics; 2008.

25. Immonen T, Brymer E, Davids K, Liukkonen J, Jaakkola T. An ecological conceptualization of extreme sports. Front Psychol. 2018;9. https://doi.org/1 0.3389/fpsyg.2018.01274

26. Davids K, Araújo D, Vilar L, Renshaw I, Pinder R. An ecological dynamics approach to skill acquisition: implications for development of talent in sport. Talent Dev Excell. 2013;5(1):21-34

27. Orth D, Davids K, Araújo D, Renshaw I, Passos P. Effects of a defender on run-up velocity and ball speed when crossing a football. Eur J Sport Sci. 2014;14:316-23.

28. Greenwood D, Davids K, Renshaw I. The role of a vertical reference point in changing gait regulation in cricket run-ups. Eur J Sport Sci. 2016;16(7):794800. https://doi.org/10.1080/17461391.2016.1151943. 
29. Cordovil R, Araújo D, Davids K, Gouveia L, Barreiros J, Fernandes O, et al. The influence of instructions and body-scaling as constraints on decisionmaking processes in team sports. Eur J Sport Sci. 2009;9(3):169-79. https:// doi.org/10.1080/17461390902763417.

30. Mooney R, Corley G, Godfrey A, Osborough C, Newell J, Quinlan LR, et al. Analysis of swimming performance: perceptions and practices of US-based swimming coaches. J Sports Sci. 2016;34(11):997-1005. https://doi.org/10.1 080/02640414.2015.1085074.

31. Balagué N, Pol R, Torrents C, Ric A, Hristovski R. On the relatedness and nestedness of constraints. Sports Med-Open. 2019;5(1):6. https://doi.org/1 0.1186/s40798-019-0178-Z

32. Robertson S, Spencer B, Back N, Farrow D. A rule induction framework for the determination of representative learning design in skilled performance. J Sport Sci. 2019;37(11):1280-5. https://doi.org/10.1080/02640414.2018.1 555905.

33. Miah A. Sport 2.0: Transforming sports for a digital world. Cambridge: The MIT Press; 2017

34. O'Donoghue P. Research methods for sports performance analysis: Routledge; 2009. https://doi.org/10.4324/9780203878309.

35. Gudmundsson J, Wolle T. Football analysis using spatio-temporal tools. Comput Environ Urban Syst. 2014;47:16-27. https://doi.org/10.1016/j. compenvurbsys.2013.09.004.

36. Gudmundsson J, Horton M. Spatio-temporal analysis of team sports. ACM Computing Surveys (CSUR). 2017;50(2):22.

37. Le HM, Carr P, Yue Y, Lucey P. Data-driven ghosting using deep imitation learning. Proceeding of the 11th MIT Sloan Sports Analytics Conference 2017. Boston: MIT; 2017.

38. Nibali A, He Z, Morgan S, Greenwood D, editors. Extraction and classification of diving clips from continuous video footage. Proceedings of the IEEE Conference on Computer Vision and Pattern Recognition Workshops; 2017.

39. Joshi A, Tripathi V, Soni R, Bhattacharyya P, Carman MJ, editors. Emogram: an open-source time sequence-based emotion tracker and its innovative applications. Workshops at the Thirtieth AAAI Conference on Artificial Intelligence; 2016

40. Wang JT-y. Pupil dilation and eye tracking. A handbook of process tracing methods for decision research: a critical review and user's guide 2011:185204

41. Corbett DM, Sweeting AJ, Robertson S. Weak relationships between stint duration, physical and skilled match performance in Australian Football. Front Physiol. 2017;8:820. https://doi.org/10.3389/fphys.2017.00820.

42. Morgan S, editor. Detecting spatial trends in hockey using frequent item sets. Proceedings of the 8th International Symposium on Computer Science in Sport; 2011.

43. Kempton T, Kennedy N, Coutts AJ. The expected value of possession in professional rugby league match-play. J Sports Sci. 2016;34(7):645-50. https://doi.org/10.1080/02640414.2015.1066511.

44. O'Shaughnessy DM. Possession versus position: strategic evaluation in AFL. J Sports Sci Med. 2006;5(4):533

45. Slade DG. Do the structures used by international hockey coaches for practising field-goal shooting reflect game centred learning within a representative learning design? Int J Sports Sci Coach. 2015;10(4):655-68. https://doi.org/10.1260/1747-9541.10.4.655

46. Hughes $M$, Franks I. Notational analysis of sport, 2nd edn: systems for better coaching and performance in sport. London: Routledge; 2004a.

47. Al Dhanhani A, Damiani E, Mizouni R, Wang D. Framework for traffic event detection using Shapelet Transform. Eng Appl Artif Intel. 2019;82:226-35.

48. Pocock C, Bezodis NE, Davids K, North JS. Hot hands, cold feet? Investigating effects of interacting constraints on place kicking performance at the 2015 Rugby Union World Cup. Eur J Sport Sci. 2018;18(10):1309-16.

49. Goldsberry K. Courtvision: new visual and spatial analytics for the nba. In 2012 MIT Sloan sports analytics conference. Boston. 2012;9:12-15.

50. Higham DG, Hopkins WG, Pyne DB, Anson JM. Performance indicators related to points scoring and winning in international rugby sevens. J Sports Sci Med. 2014;13(2):358-64.

51. Skinner B. The problem of shot selection in basketball. PloS one. 2012;7(1): e30776. https://doi.org/10.1371/journal.pone.0030776.

52. Bar-Eli M, Avugos S, Raab M. Twenty years of "hot hand" research: review and critique. Psychol Sport Exerc. 2006;7(6):525-53. https://doi.org/10.1016/j. psychsport.2006.03.001

53. Reich BJ, Hodges JS, Carlin BP, Reich AM. A spatial analysis of basketball shot chart data. Am Stat. 2006;60(1):3-12. https://doi.org/10.1198/000313006X90305.
54. Rein R, Raabe D, Memmert D. Which pass is better? Novel approaches to assess passing effectiveness in elite soccer Hum Mov Sci. 2017;55:172-81. https://doi.org/10.1016/j.humov.2017.07.010.

55. Alexander JP, Spencer B, Sweeting AJ, Mara JK, Robertson S. The influence of match phase and field position on collective team behaviour in Australian rules football. J Sports Sci. 2019;37(15):1699-707.

56. Engelniederhammer A, Papastefanou G, Xiang L. Crowding density in urban environment and its effects on emotional responding of pedestrians: using wearable device technology with sensors capturing proximity and psychophysiological emotion responses while walking in the street. J Human Behav Soc Environ. 2019;29(5):630-46. https://doi.org/10.1080/1 0911359.2019 .1579149

57. Blair S, Roberston S, Duthie G, Ball K. The effect of altering distance on goalkicking technique in Australian Football. ISBS Proceed Arch. 2018;36(1):358

58. Blair S, Duthie G, Robertson S, Hopkins W, Ball K. Concurrent validation of an inertial measurement system to quantify kicking biomechanics in four football codes. J Biomech. 2018;73:24-32. https://doi.org/10.1016/j. jbiomech.2018.03.031.

59. Emani S, Soman K, Variyar VS, Adarsh S. Obstacle detection and distance estimation for autonomous electric vehicle using stereo vision and DNN. Soft Computing and Signal Processing. Singapore: Springer; 2019. p. 639-48.

60. Almonroeder TG, Tighe SM, Miller TM, Lanning CR. The influence of fatigue on decision-making in athletes: a systematic review. Sports Biomech. 2018; 14:1-14.

61. Sarmento H, Clemente FM, Araújo D, Davids K, McRobert A, Figueiredo A. What performance analysts need to know about research trends in association football (2012-2016): A systematic review. Sports Med. 2018; 48(4):799-836.

62. Nimmins J, Strafford B, Stone J. Effect of puck mass as a task constraint on skilled and less-skilled ice hockey players performance. J Motor Learn Dev. 2019;7(1):1-12. https://doi.org/10.1123/jmld.2017-0058.

63. Fitzpatrick A, Davids K, Stone JA. Effects of scaling task constraints on emergent behaviours in children's racquet sports performance. Hum Mov Sci. 2018;58:80-7. https://doi.org/10.1016/j.humov.2018.01.007.

64. Nugraha U, Wahyu AP. Weight measurement and identification of cow type using computer vision method. Int J Eng Technol. 2018;7(4.34):291-4.

65. Wulf G, Lewthwaite R. Optimizing performance through intrinsic motivation and attention for learning: the OPTIMAL theory of motor learning. Psychon Bull Rev. 2016;23(5):1382-414. https://doi.org/10.3758/s13423-015-0999-9.

66. Wrisberg CA. Sport skill instruction for coaches. Champaign: Human Kinetics; 2007

67. Gundogdu B, Saraclar M. Similarity measure optimization for target detection: a case study for detection of keywords in telephone conversations. Operations Research for Military Organizations. IGl Global; 2019. p. 347-374. https://doi.org/10.4018/978-1-5225-5513-1.ch015.

68. Cust EE, Ball K, Sweeting A, Robertson S, editors. Biomechanical characteristics of elite female Australian rules football preferred and non-preferred drop punt kicks. Proceedings of the 7th International Conference on Sport Sciences Research and Technology Support (icSPORTS 2019); 2019: SCITEPRESS.

69. Ball K. Kinematic comparison of the preferred and non-preferred foot punt kick. J Sports Sci. 2011;29(14):1545-52. https://doi.org/10.1080/02640414.2 011.605163

70. Klusemann MJ, Pyne DB, Foster C, Drinkwater EJ. Optimising technical skills and physical loading in small-sided basketball games. J Sports Sci. 2012; 30(14):1463-71. https://doi.org/10.1080/02640414.2012.712714.

71. Dong JG. The role of heart rate variability in sports physiology. Exp Ther Med. 2016;11(5):1531-6. https://doi.org/10.3892/etm.2016.3104.

72. Zhang F, Yu Y, Zhong J, editors. Research status and development prospects of human vital signs monitoring clothing. IOP Conf Se Earth Environ Sci; 2019

73. Russell S, Jenkins D, Rynne S, Halson SL, Kelly V. What is mental fatigue in elite sport? Perceptions from athletes and staff. Eur J Sport Sci. 2019;19(10): 1367-76. https://doi.org/10.1080/17461391.2019.1618397.

74. Chuang K-C, Lin Y-P. Cost-efficient, portable, and custom multi-subject electroencephalogram recording system. IEEE Access. 2019;7:56760-9. https://doi.org/10.1109/ACCESS.2019.2914088.

75. Piette J, Anand S, Zhang K. Scoring and shooting abilities of NBA players. J Quant Anal in Sports. 2010;6(1):1.

76. Anshel MH, Sutarso T, Jubenville C. Racial and gender differences on sources of acute stress and coping style among competitive athletes. J Soc Psychol. 2009;149(2):159-78. https://doi.org/10.3200/SOCP.149.2.159-178. 
77. Davids K, Button C, Araújo D, Renshaw I, Hristovski R. Movement models from sports provide representative task constraints for studying adaptive behavior in human movement systems. Adaptive behav. 2006;14(1):73-95. https://doi.org/10.1177/105971230601400103.

78. Garcia-Alonso J, Berrocal J, Pérez-Vereda A, Galán-Jiménez J, Canal C, Murillo JM. Using bluetooth low energy advertisements for the detection of people temporal proximity patterns. Mobile Inform Syst. 2020;2020:1-17.

79. Halson SL. Monitoring training load to understand fatigue in athletes. Sports Med. 2014;44(2):139-47. https://doi.org/10.1007/s40279-014-0253-z.

80. Gastin PB, Fahrner B, Meyer D, Robinson D, Cook JL. Influence of physical fitness, age, experience, and weekly training load on match performance in elite Australian football. J Strength Cond Res. 2013;27(5):1272-9. https://doi. org/10.1519/JSC.0b013e318267925f.

81. Li J, Ma Q, Chan AH, Man S. Health monitoring through wearable technologies for older adults: smart wearables acceptance model. Appl Ergon. 2019;75:162-9. https://doi.org/10.1016/j.apergo.2018.10.006.

82. Juliff $L E$, Halson SL, Peiffer JJ. Understanding sleep disturbance in athletes prior to important competitions. J Sci Med Sport. 2015;18(1):13-8. https:// doi.org/10.1016/j.jsams.2014.02.007.

83. Halson SL, Juliff LE. Sleep, sport, and the brain. In: Mark R. Wilson, Vincent Walsh and Beth Parkin, editors, Progress in Brain Research, Vol. 234, Amsterdam: Academic Pres; 2017.

84. Toften S, Pallesen S, Hrozanova M, Moen F, Grønli J. Validation of sleep stage classification using non-contact radar technology and machine learning (Somnofy ${ }^{\oplus}$ ). Sleep Med. 2020;75:54-61. https://doi.org/10.1016/j. sleep.2020.02.022.

85. Robertson S, Joyce D. Evaluating strategic periodisation in team sport. J Sports Sci. 2018;36(3):279-85. https://doi.org/10.1080/02640414.2017.1300315.

86. Franks A, Miller A, Bornn L, Goldsberry K. Characterizing the spatial structure of defensive skill in professional basketball. Ann Appl Stat. 2015:9(1):94-121. https://doi.org/10.1214/14-AOAS799.

87. Tan TYH, Chow JY, Duarte R, Davids K. Manipulating task constraints shapes emergence of herding tendencies in team games performance. Int J Sports Sci Coach. 2017;12(5):595-602. https://doi.org/10.1177/1747954117727661.

88. Wang J, Fox I, Skaza J, Linck N, Singh S, Wiens J. The advantage of doubling: a deep reinforcement learning approach to studying the double team in the NBA. arXiv preprint arXiv:1803.02940. 2018.

89. Milanese C, Piscitelli F, Lampis C, Zancanaro C. Anthropometry and body composition of female handball players according to competitive level or the playing position. J Sports Sci. 2011;29(12):1301-9. https://doi.org/10.1 080/02640414.2011.591419.

90. Goldman M, Rao JM, editors. Effort vs. concentration: the asymmetric impact of pressure on NBA performance. Proceedings of the MIT Sloan sports analytics conference; 2012.

91. Dellal A, Hill-Haas S, Lago-Penas C, Chamari K. Small-sided games in soccer: amateur vs. professional players' physiological responses, physical, and technical activities. J Strength Cond Res. 2011;25(9):2371-81. https://doi. org/10.1519/JSC.0b013e3181fb4296

92. Soroka A, Lago-Peñas C. The effect of a succession of matches on the physical performance of elite football players during the World Cup Brazil 2014. Int J Perform Anal Sport. 2016;16(2):434-41. https://doi.org/10.1080/24 748668.2016.11868899.

93. Bartlett $M$, James I, Ford $M$, Jennings-Temple M. Testing natural turf sports surfaces: the value of performance quality standards. Proceedings of the Institution of Mechanical Engineers, Part P. J Sports Eng Technol. 2009; 223(1):21-9.

94. Crowther RH, Gorman AD, Spratford WA, Sayers MG, Kountouris A. Examining environmental constraints in sport: Spin characteristics of two cricket pitches with contrasting soil properties. Eur J Sport Sci. 2019:1-8.

95. Liu L, Zhang K, Fu S, Liu B, Huang M, Zhang Z, et al. Rapid magnetic susceptibility measurement for obtaining superficial soil layer thickness and its erosion monitoring implications. Geoderma. 2019:351:163-73. https://doi. org/10.1016/j.geoderma.2019.05.030.

96. Kelly DM, Drust B. The effect of pitch dimensions on heart rate responses and technical demands of small-sided soccer games in elite players. J Sci Med Sport. 2009;12(4):475-9. https://doi.org/10.1016/j.jsams.2008.01.010.

97. Thornes J. The effect of weather on sport. Weather. 1977;32(7):258-68. https://doi.org/10.1002/j.1477-8696.1977.tb04568.x.

98. Ely MR, Cheuvront SN, Roberts WO, Montain SJ. Impact of weather on marathon-running performance. Med Sci Sports Exerc. 2007;39(3):487-93. https://doi.org/10.1249/mss.0b013e31802d3aba.
99. Reitmann S, Alam S, Schultz M, editors. Advanced quantification of weather impact on air traffic management. 13th USA/Europe Air Traffic Management Research and Development Seminar; Vienna, Austria. 2019.

100. Gama J, Dias G, Couceiro M, Passos P, Davids K, Ribeiro J. An ecological dynamics rationale to explain home advantage in professional football. Int J Modern Physics C. 2016;27(09):1650102. https://doi.org/10.1142/S012918311 6501023.

101. Ashkezari-Toussi S, Kamel M, Sadoghi-Yazdi H. Emotional maps based on social networks data to analyze cities emotional structure and measure their emotional similarity. Cities. 2019;86:113-24. https://doi.org/10.1016/j.cities.2 018.09.009.

102. Pettigrew S, editor. Assessing the offensive productivity of NHL players using in-game win probabilities. 9th annual MIT sloan sports analytics conference; 2015.

103. Sandholtz N, Bornn L, editors. Replaying the NBA. The 12th Annual MIT Sloan Sports Analytics Conference; 2018.

104. Andrienko G, Andrienko N, Budziak G, Dykes J, Fuchs G, Von Landesberger T et al. Visual analysis of pressure in football. Data Mining and Knowledge Discovery. 2017

105. Araújo D, Davids K. Team synergies in sport: theory and measures. Front Psychol. 2016;7:1449.

106. Araújo D, Ramos JP, Lopes RJ. Shared affordances guide interpersonal synergies in sport teams. Interpersonal coordination and performance in social systems 2016:165.

107. Newcombe DJ, Roberts WM, Renshaw I, Davids K. The effectiveness of constraint-led training on skill development in interceptive sports: a systematic review (Clark, McEwan and Christie)-a commentary. Int J Sports Sci Coach. 2019;14(2):241-54. https://doi.org/10.1177/1747954119829918.

108. Clemente FM, Martins FM, Couceiro MS, Mendes RS, Figueiredo AJ. Developing a tactical metric to estimate the defensive area of soccer teams: the defensive play area. Proceedings of the Institution of Mechanical Engineers, Part P. J Sports Eng Technol. 2016;230(2):124-32.

109. McGarry T. Applied and theoretical perspectives of performance analysis in sport: Scientific issues and challenges. Int J Perform Anal Sport. 2009;9(1): 128-40. https://doi.org/10.1080/24748668.2009.11868469.

110. Ireland D, Dawson B, Peeling $P$, Lester L, Heasman J, Rogalski B. Do we train how we play? Investigating skill patterns in Australian football. Sci Med Football. 2019:1-10.

111. Davids K, Araújo D. The concept of 'organismic asymmetry' in sport science. J Sci Med Sport. 2010;13(6):633-40. https://doi.org/10.1016/j.jsams.2010.05.002

112. Ghazikhanian A, Cottrell S. A comparison of sports regulations on the use of wearable technology \& data collection. LawInSport, LawInSport. 2018. https://www.lawinsport.com/topics/item/a-comparison-of-sports-regula tions-on-the-use-of-wearable-technology-data-collection?tmpl= component\&print=1. Accessed 26/11/2019 2019.

113. Liu S, Wang $X$, Liu M, Zhu J. Towards better analysis of machine learning models: a visual analytics perspective. Visual Informatics. 2017;1(1):48-56. https://doi.org/10.1016/j.visinf.2017.01.006

114. Farrow D, Robertson S. Development of a skill acquisition periodisation framework for high-performance sport. Sports Med. 2017;47(6):1043-54. https://doi.org/10.1007/s40279-016-0646-2.

115. Glazier PS. Game, set and match? Substantive issues and future directions in performance analysis. Sports Med. 2010;40(8):625-34. https://doi.org/10.21 65/11534970-000000000-00000.

116. Couceiro MS, Dias G, Araújo D, Davids K. The ARCANE project: how an ecological dynamics framework can enhance performance assessment and prediction in football. Sports Med. 2016;46(12):1781-6. https://doi.org/10.1 007/s40279-016-0549-2.

117. McLean S, Hulme A, Mooney M, Read GJM, Bedford A, Salmon PM. A systems approach to performance analysis in women's netball: using work domain analysis to model elite netball performance. Front Psychol. 2019;10: 201. https://doi.org/10.3389/fpsyg.2019.00201.

118. Analytics. in Oxford Dictionary. Oxford Dictionary. 2020. https://en. oxforddictionaries.com/definition/analytics. Accessed 20 July 2020.

119. Alpaydin E. Introduction to machine learning. Cambridge: The MIT Press; 2010.

120. Cervone D, D'Amour A, Bornn L, Goldsberry K, editors. POINTWISE: predicting points and valuing decisions in real time with NBA optical tracking data. MIT Sloan Sports Analytics Confernce; 2014; Hynes Convention Centre.

121. Deshpande S, Thakare V. Data mining system and applications: a review. Int J Distributed Parallel Syst. 2010;1(1):32-44. https://doi.org/10.5121/ijdps.201 0.1103. 
122. Benito Santos A, Theron R, Losada A, Sampaio JE, Lago-Peñas C. Data-driven visual performance analysis in soccer: an exploratory prototype. Front Psychol. 2018;9:2416. https://doi.org/10.3389/fpsyg.2018.02416.

123. Robertson S, Back N, Bartlett JD. Explaining match outcome in elite Australian rules football using team performance indicators. J Sports Sci. 2016;34(7):637-44. https://doi.org/10.1080/02640414.2015.1066026.

124. Schelling $X$, Robertson S. A development framework for decision support systems in high-performance sport. Int J Comput Sci Sport. 2020;19(1):1-23. https://doi.org/10.2478/ijcss-2020-0001.

125. Sicilia A, Pelechrinis K, Goldsberry K. DeepHoops: evaluating micro-actions in basketball using deep feature representations of spatio-temporal data. arXiv preprint arXiv:190208081. 2019.

126. James G, Witten D, Hastie T, Tibshirani R. An introduction to statistical learning. New York: Springer; 2013.

127. Duro DC, Franklin SE, Dubé MG. A comparison of pixel-based and objectbased image analysis with selected machine learning algorithms for the classification of agricultural landscapes using SPOT-5 HRG imagery. Remote Sens Environ. 2012;118:259-72. https://doi.org/10.1016/j.rse.2011.11.020.

128. Williams N, Zander S, Armitage G. A preliminary performance comparison of five machine learning algorithms for practical IP traffic flow classification. ACM SIGCOMM Comput Commun Review. 2006;36(5):5-16. https://doi.org/1 $0.1145 / 1163593.1163596$

129. Fahey-Gilmour J, Dawson B, Peeling P, Heasman J, Rogalski B. Multifactorial analysis of factors influencing elite Australian football match outcomes: a machine learning approach. Int J Comput Sci Sport. 2019;18(3):100-24. https://doi.org/10.2478/ijcss-2019-0020.

130. Fernández J, Bornn L. Wide open spaces: a statistical technique for measuring space creation in professional soccer. Sloan Sports Analytics Conference; 2018.

131. Spencer B, Morgan S, Zeleznikow J, Robertson S. Measuring player density in Australian Rules football using Gaussian Mixture models. In: Proceedings of the Complex Systems in Sport, International Congress Linking Theory and Practice. Barcelona; 2017. p 172-4.

132. Rhee C, Rao HR. Evaluation of decision support systems. Handbook on Decision Support Systems 2. Berlin: Springer; 2008. p. 313-27.

133. Robertson $S$, Joyce D. Bounded rationality revisited: making sense of complexity in applied sport science. SportRxiv. 2019;33(1):1-8. https://doi. org/10.1080/02640414.2014.925572

134. Robertson S. Linking sport science and analytics in a professional football club. Football analytics, now and beyond: a deep dive into the current state of advanced data analytics. Barca Innovation Hub; 2019. p. 134-43.

135. Morgan S, Williams MD, Barnes C. Applying decision tree induction for identification of important attributes in one-versus-one player interactions: a hockey exemplar. J Sports Sci. 2013;31(10):1031-7. https://doi.org/10.1080/ 02640414.2013.770906.

136. Green M. Toward a perceptual science of multidimensional data visualization: Bertin and beyond. ERGO/GERO Human Factors Sci. 1998:8:1-30.

137. Goldstone RL. Perceptual learning. Annu Rev Psychol. 1998;49(1):585-612. https://doi.org/10.1146/annurev.psych.49.1.585.

138. Spence I, Lewandowsky S. Displaying proportions and percentages. Appl Cogn Psychol. 1991;5(1):61-77. https://doi.org/10.1002/acp.2350050106.

139. Kale A, Nguyen F, Kay M, Hullman J. Hypothetical outcome plots help untrained observers judge trends in ambiguous data. IEEE Trans Vis Comput Graph. 2018;25(1):892-902.

140. Padilla L, Creem-Regehr SH, Thompson W. The powerful influence of marks: visual and knowledge-driven processing in hurricane track displays. J Exp Psychol-Appl. 2019.

141. Padilla L, Ruginski IT, Creem-Regehr SH. Effects of ensemble and summary displays on interpretations of geospatial uncertainty data. Cognitive research: principles and implications. 2017;2(1):1-16.

142. Fagerlin A, Zikmund-Fisher BJ, Ubel PA. Helping patients decide: ten steps to better risk communication. J Natl Cancer Inst. 2011;103(19):1436-43. https://doi.org/10.1093/jnci/djr318.

143. Fernandes M, Walls L, Munson S, Hullman J, Kay M, editors. Uncertainty displays using quantile dotplots or CDFs improve transit decision-making. Proceedings of the $2018 \mathrm{CHI}$ Conference on Human Factors in Computing Systems; 2018

144. Cawthon N, Moere AV, editors. The effect of aesthetic on the usability of data visualization. 2007 11th International Conference Information Visualization (IV'07); 2007: IEEE.
145. Pinker S. A theory of graph comprehension. Artificial intelligence and the future of testing; 1990. p. 73-126.

146. Hullman J, Qiao X, Correll M, Kale A, Kay M. In pursuit of error: a survey of uncertainty visualization evaluation. IEEE Trans Vis Comput Graph. 2018; 25(1):903-13.

147. Fagerlin A, Wang C, Ubel PA. Reducing the influence of anecdotal reasoning on people's health care decisions: is a picture worth a thousand statistics? Med Decis Making. 2005;25(4):398-405. https://doi.org/10.1177/02 $72989 \times 05278931$.

148. Arnott D. Cognitive biases and decision support systems development: a design science approach. Inform Syst J. 2006;16(1):55-78. https://doi.org/1 0.1111/j.1365-2575.2006.00208.x.

149. Hollands J, Spence I. Judging proportion with graphs: the summation model. Appl Cogn Psychol. 1998;12(2):173-90. https://doi.org/10.1002/(SICI)1 099-0720(199804)12:2<173::AID-ACP499>3.0.CO;2-K.

150. Griffin JA, McLellan CP, Presland J, Woods CT, Keogh JW. Effect of defensive pressure on international women's rugby sevens attacking skills frequency and execution. Int J Sports Sci Coach. 2017;12(6):716-24. https://doi.org/1 $0.1177 / 1747954117738887$.

151. Wilke CO. Fundamentals of data visualization: a primer on making informative and compelling figures. Sebastopol: O'Reilly Media; 2019.

152. Larkin $J H$, Simon HA. Why a diagram is (sometimes) worth ten thousand words. Cognit Sci. 1987;11(1):65-100. https://doi.org/10.1111/j.1551-6708.1 987.tb00863.x.

\section{Publisher's Note}

Springer Nature remains neutral with regard to jurisdictional claims in published maps and institutional affiliations.

\section{Submit your manuscript to a SpringerOpen ${ }^{\circ}$ journal and benefit from:}

- Convenient online submission

- Rigorous peer review

- Open access: articles freely available online

- High visibility within the field

- Retaining the copyright to your article

Submit your next manuscript at $>$ springeropen.com 